\title{
Sustainable Architecture: Practices and Methods to Achieve Sustainability in Construction
}

\author{
Bruno Marques and Carlos Rafael Loureiro
}

\begin{abstract}
This paper discusses the concept of sustainable architecture, seeking to discuss more accurately the theme of recycling, optimization and lifecycle of building materials, and their importance in saving natural resources, energy performance, building construction, and to what extent experience and training can influence the practice of a more sustainable architecture. Thus, the paper intends to make a small contribution regarding the awareness of those involved in the construction sector, encouraging them to adopt new attitudes and develop new practices, since the current ones are hopelessly unsustainable.
\end{abstract}

Index Terms-Sustainability, constructive materials, optimization of resources in construction.

\section{INTRODUCTION}

Nowadays, due to a growing understanding of human interaction with nature, it is widely accepted by the scientific community that consuming energy from non-renewable sources has caused serious environmental damage. Among human activities, the construction industry stands out as one of the sectors that consume more raw materials and energy, this way, no society can achieve a sustainable development unless the construction sector, which gives it support, goes through deep transformations. The production chain of this sector has significant environmental impacts at all stages of its process... Any society seriously concerned about this issue should put the improvement of the construction sector as a priority [1]. Facing these circumstances, the actors in the construction sector are trying to make their activities more sustainable, adopting the principles of bioclimatic design, and looking for solutions in building materials that are less harmful to the environment. Most environmentalists believe nowadays, according to Fig. 1, that is possible to reach a balance between economic growth, social justice and environmental preservation, this makes more sense than ever, since it promotes an economy based on a type of growth that provides a sensible distribution of benefits and a more respectful use of natural resources.

The process of urban expansion has caused many difficulties with the large amount of waste generated by the construction and demolition of buildings. When associated with the increasing cost of raw materials, it has become difficult to manage resources in this sector. Thus, in addition to the effort to increase the optimization of construction materials in building, the recycling of waste has become very important, since most of this waste has the potential to be

Manuscript received July 7, 2012; revised December 29, 2012.

Bruno Marques is with the Centro de Estudos Africanos da Universidade do Porto, Portugal (e-mail: arqbrunomarques@gmail.com). transformed in a new source of raw materials. The search for efficiency in managing resources requires extensive knowledge of the materials life cycle, which should not be limited only to their use in the building process, but extended to every aspect of the material life cycle, from the extraction until their total destruction.

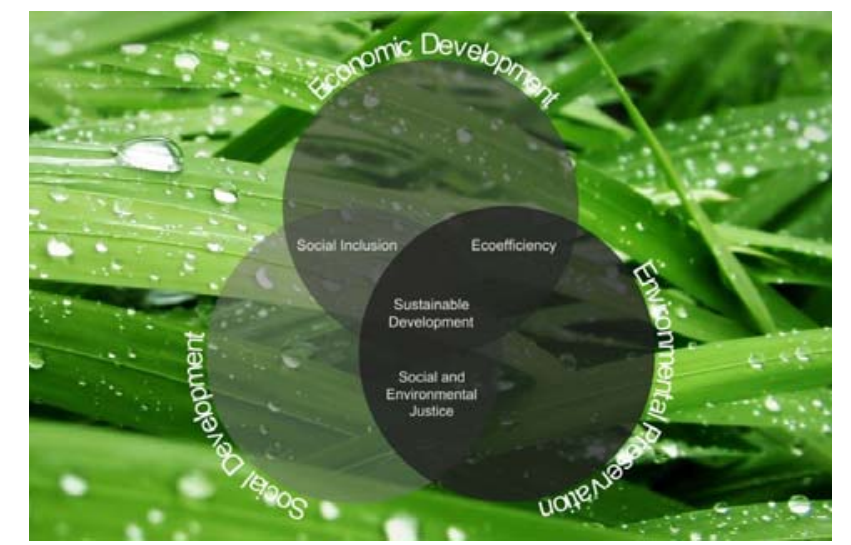

Fig. 1. Sustainable development. This concept defends that current needs can be met without compromising the needs of future generations, consisting essentially of three areas - social, economic and environmental.

\section{The Problem of NATURAL Resources}

The environmental issue and the rational use of resources have been highlighted as one of the most discussed issues across all sectors of society. Therefore the population is more alert about the problems associated with the construction industry, since the construction sector is responsible for this situation. Although construction is considered an important sector in our society, through the role it plays in the economy by creating jobs and boosting the country's growth and development, nonetheless it is a sector that consumes a lot of energy and contributes the most to Earth's pollution, due to its production methods. So it is imperative to realize the source of the problems in order to find solutions that can maximize the potential and minimize the waste of construction materials. This depends primarily on how natural resources are managed.

Man has always taken advantage of natural resources, but the population growth of the planet, especially in the last century, also increased the need for raw materials. Although the crust of the Earth contains a huge amount of resources, it is believed that technological evolution will not allow the extraction of these resources so as to satisfy human needs. Thus some researchers are developing studies that estimate the time when some of the main resources used by mankind will be exhausted, such as crude oil (41 years), natural gas (63 years), iron (95), charcoal (150 years), among others. However, these estimates would be quite different if the 
consumption patterns of developed countries would spread to the rest of the world, in which case the resources we have at our disposal would run out much faster.

It is well known that there are serious environmental problems associated with the extraction of raw materials and the production of building materials. There are, nevertheless, authors that do not believe the greenhouse effect is the more serious consequence for the environment, but this does not mean we should ignore the high levels of carbon dioxide in the atmosphere, since they might contribute to various respiratory pathologies, such as bronchitis and asthma.

Today, we know that the most damaging impacts to the planet come from the extraction of resources and its impact on the site, drastically reducing biodiversity, altering the landscape and, in the case of mining, generating large amounts of waste. Leaks or spills are often associated with the extraction and transportation of raw materials, and these are the cases most harmful to the environment. According to L. P. Hedeberg from The Natural Step movement, there are four conditions regarding the use of raw materials that we must comply with in order to achieve a sustainable society: do not take more out of the crust of the Earth than can be replaced; do not use man-made materials which take a long time to decompose; maintain the conditions for Nature to keep its production and its diversity; use resources efficiently and correctly - stop being wasteful [2]. While all the conditions presented above should be taken into account in the way we manage natural resources, it is impossible to apply the first three conditions in the short term, since that would bring results too radical for a suitable adaptation of society. However, the fourth condition must be taken into particular attention by architects and engineers, as they are primarily responsible for choice and management of the building materials.

\section{THE RELEVANCE OF ENERGY ISSUES IN THE CONSTRUCTION SECTOR}

Energy efficiency is a key point in the search for sustainability in the construction sector, as shown in Fig. 2. Both the architect as the future user of the building are responsible for this matter, since they decide how to build it. The first is the one who creates the project and the latter dictates its demands, thereby the ideal is that both parts share a concern about the sustainability of the building, and if this does not happen, the architect should be the first to warn the customer on this issue.

In the late eighties, the concept of embodied energy in building materials was first adopted in the United States. According to this concept, the extraction of raw materials, the production and transportation of construction materials, and the building construction could be translated into energy expended during all these processes. As a result of studying this concept, we started to realize that one of the most effective ways to save energy was to preserve and reuse existing buildings. Up until recently, the concept of embodied energy has never gained great visibility outside some groups of environmental protection, since preserving a building by its asset value was more appealing than doing it in order to save energy and resources. However, with the current energy costs and the growing scarcity of raw materials, it makes even more sense to understand the best way to take advantage of existing buildings.

With regard to environmental and energy issues, it is more advantageous to preserve and reuse existing buildings. However, this practice depends on the durability of the materials used, which can be defined as their ability to sustain a minimum performance under degradative factors [3]. Thus, there is a clear advantage in using materials that are as durable as possible, allowing the buildings to have a longer service life. In contrast, the use of materials with a reduced durability usually requires a larger number of maintenance and rehabilitation interventions and it may even be necessary to replace the component, involving the consumption of energy, raw materials and expenses with manpower. Thus, environmentally, it is preferable to use a material with high embodied energy but also high durability, instead of a material with low embodied energy but with a shorter life time, since the production of both can cause nearly the same environmental damage. It should be noted that the durability of materials does not concern only technical factors, but it has an important aesthetic factor associated, which must respond to society demands during a relatively long period of time.

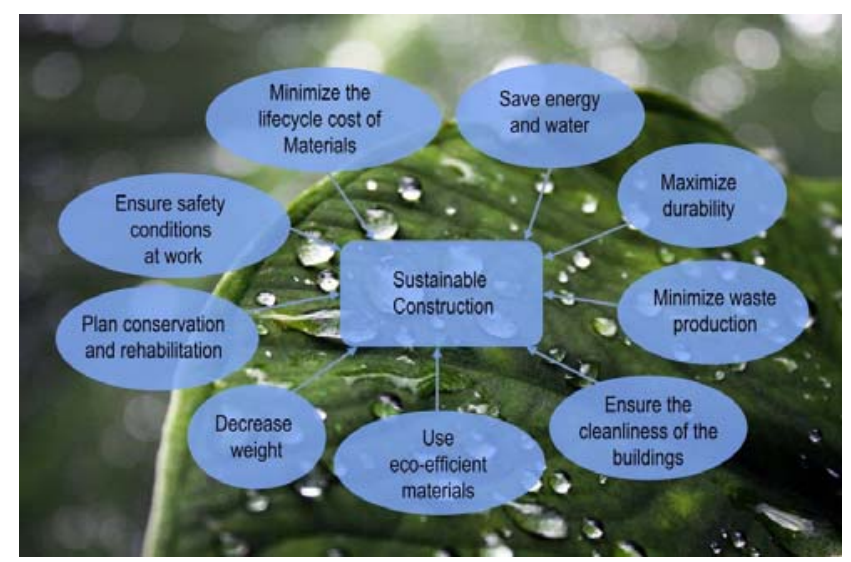

Fig. 2. Priorities to be considered in the design of a sustainable building; as it can be seen, this type of construction involves several practices.

In this context emerges another notion that is quite relevant with regard to energy saving. The thermal inertia of a building is its ability to counteract variations in temperature inside, and reduce the transfer or transmission of heat. This is due to its ability to accumulate heat in the building elements [4]. This issue is of great importance in areas with a large temperature range, within a short time. In this way, optimizing the thermal inertia in a given environment must allow the temperature inside a building to remain stable, reducing the need for any mechanical solutions to adjust the interior temperature, which in turn reduces the energy consumption of the building.

\section{Deconstruction as a Method of Resource RECOVERY}

The search for sustainability in construction leads to the development of innovative materials, together with more technologically advanced approaches. However, the practice of deconstructing buildings, when they become obsolete, is probably the most efficient, from an ecological perspective, 
this way, the recap of the Selective Demolition concept is particularly important since, nowadays, in most developed countries, there is a movement of urban renewal dictated by the need for better land use in areas of high population density [5]. In most countries of the world, the demolition of a building is still carried out with the intention that it should be as fast and inexpensive as possible, without a careful selection of the various resulting wastes. However, these criteria are changing due to the increasing amount of demolished buildings, the need of efficient land use and the environmental concerns of society. The current procedure is a Selective Demolition, seeking to deconstruct carefully and doing a screening of the different components rather than demolishing the buildings indiscriminately. This type of practice is not entirely new. During the nineteenth century, throughout Europe there have been cases of complex metallic structures, including pavilions, factories, and railway stations that were commonly used, but when for some reason they no longer made sense in their surrounding context, were dismantled and rebuilt elsewhere. However, technological developments and the latest construction methods do not favor this type of practice. What happens now is the recovery of deconstruction, since it responds to many of the current needs of the sector.

In order to carry out the deconstruction of a building it is important to realize, according to Fig. 3, that its composition consists of several layers, normally the main structure being the most enduring (approximately 50 years), while the other layers have a smaller duration and require maintenance in a considerably shorter period of time, such as the interior and exterior coatings, servicing, etc. In modern buildings there has been a tendency to incorporate the different layers in a single component. Although this may have advantages in some situations, it is not a solution that benefits the building in the long term, since the durability of materials in different layers is normally incompatible, thus resulting in different levels of degradation in the same component, invalidating future efforts for reusing and eventual recycling. It should therefore be accomplished a smooth transition between the different layers forming the building. Thus, the maintenance and replacement of the various components will be ensured, also allowing, in the demolition phase, an appropriate separation of the materials and enhancing their reuse and recycling.

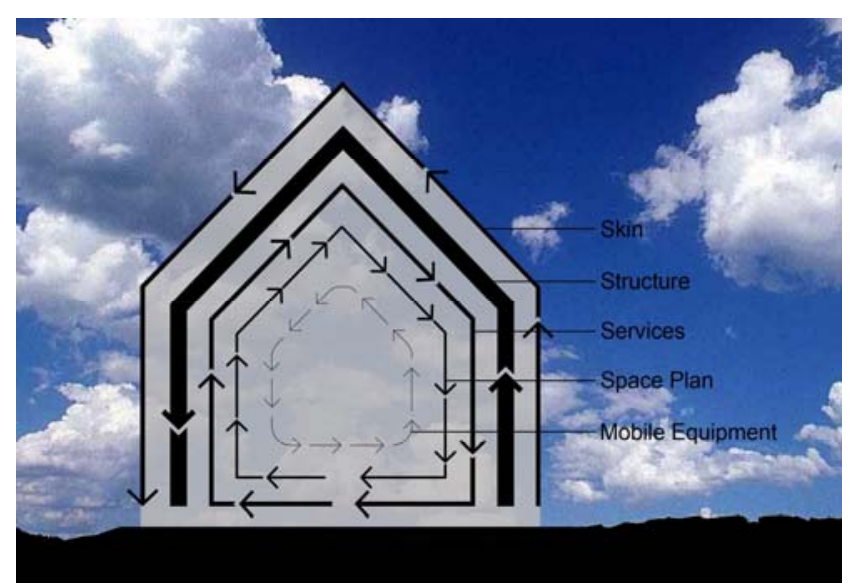

Fig. 3. A building should consist of different separate layers, allowing future maintenance operations in a layer without affecting the following ones.

\section{RECYCLING IN THE PROCESS OF CONSTRUCTION AND DEMOLITION OF BUILDINGS}

The traditional procedures for waste treatment developed in a linear model, which assumes that nature is an inexhaustible source of resources and possesses an inexhaustible capacity for waste disposal, are beginning to be replaced by a model based on extending the life cycle of building materials, together with a more efficient waste management. In this scenario, recycling emerges as a practice that presents solutions regarding how to manage the waste, with the aim of saving energy and natural resources by returning to the production cycle those materials which otherwise would have no utility. The raw materials for producing construction materials are increasingly scarce and therefore its extraction is more expensive and more difficult. The use of landfills for the deposit of waste has also produced a negative impact on people and landscapes. In addition, landfill sites are usually located far from large urban areas, implying an increased cost with transportation. On top of this, such condition comes together with the rising price of fuel, further aggravating the whole situation.

Given these circumstances, recycling has become a credible option as regards the disposal of waste from the construction and demolition of buildings. Therefore, many companies producing construction materials began to see this practice as a new source of raw materials, which tends to be increasingly important in producing construction materials. Recycling construction and demolition waste, like any other construction activity, requires basic planning to be effective. In fact, the requirements of coordinating a successful construction waste recycling effort are quite similar to the types of planning required for basic construction project management, including scheduling, training, monitoring, and recordkeeping [6]. This means that this kind of planning requires a careful thought, and if the costs of stages like transportation are not calculated correctly, it can turn all the effort economically enviable.

Many of the efforts to reduce environmental problems in the construction sector address the issue in a simplistic way, since the methods being used ignore the need for a critical reflection about the cultural values of a consumerist society, based on a production system where capital assumes too much importance at the expense of moral values.

\section{CONCLUSION}

We can conclude that the theme of sustainable architecture has currently a great visibility, so the actors in the construction sector should look for new practices that can meet the expectations of society. The scope of sustainability in architecture is to adopt different strategies, in order to reduce the energy consumption of buildings and the pollution associated with this activity. Among all the issues dealing with sustainability in construction, the way to manage the construction materials is certainly the most significant. Thus, the management of construction materials should not be limited only to the construction process, since in order to ensure its efficiency there must be a broad knowledge of all the production processes of the material. 
There are several practices enabling the optimization of construction materials, including selective demolition and waste recycling, which are certainly the most efficient, since they promote the extension of the materials life cycle, reducing the dependence of pure raw materials in the industry.

\section{REFERENCES}

[1] P. Paiva, A Reciclagem na Construção Civil: Como Economia de Custos, Bacharelato em Ciências Contábeis, Faculdade de Economia, Administração e Contabilidade de Ribeirão Preto.

[2] B. Berge, The Ecology of Building Materials. 1st edition. Oxford: Architectural Press, 2001

[3] Garantia da Durabilidade dos Materiais de Construção. (Ouctober 13 2012). [Online]. Available: http://www.apcmc.pt

[4] Thermal Inertia. (March 27, 2012). [Online]. Available: http://www.futureng.pt

[5] C. Lourenço, Optimização de Sistemas de Demolição - Demolição Selectiva. Departamento de Engenharia Civil e Arquitectura, 2007.

[6] G. Winkler, Recycling Construction and Demolition Waste A LEEDBased Toolkit. $1^{\text {a }}$ Edition, McGraw-Hill, 2010.

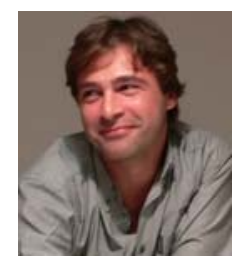

Bruno Gomes Marques was born in Espinho, Portugal 1973, PhD in Civil Engineering at Faculty of Engineering University of Oporto,Portugal, 2011. $\mathrm{PhD}$ in Architecture at Valladolid University, Spain, 2010. Master degree in Urban Planning at Faculty of Architecture, University of Oporto, Portugal. Associate Regent Professor, Researcher at Master degree in Architecture and Urbanism, at Faculty of Architecture and Arts, University Lusíada Porto. Researcher and coordinator of NGO CEAUP for the area of Sustained Economic Development in Africa. Issues and projects of applied research. applied research in Africa eco-development (architecture and urbanism), Developed research in the field of Civil Engineering, within a multidiciplinary research team, with the title: Energy Efficiency in Residential Buildings - From Theory to Practice. Application of the Principles of Bioclimatic Architecture to Practice at Dept. of Civil Engineering, Faculty of Engineering University of Oporto.

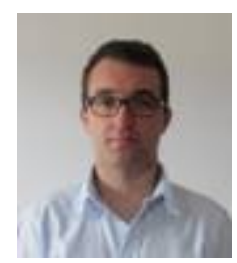

Rafael Loureiro was born in Portugal on 1986 in the town of Penafiel. He completed his primary and secondary education in his hometown, where he attended classes related to the arts. In 2004 he was admitted to the Oporto Lusíada University where he studied architecture. He finished his degree in 2008 and opted to develop a master's thesis right away, completing it in 2012, where he developed a research around sustainable architecture, deepening yet the issue of sustainability of building materials, building deconstruction and recycling waste from construction and demolition. With regard to professional experience is to highlight a broad experience in the field of Catering, started in 2001 and extending to the present time, and some work in the area of telecommunications. 